\title{
Fusion of Seashell Nacre and Marine Bioadhesive Analogs: High-Strength Nanocomposite by Layer-by-Layer Assembly of Clay and L-3,4-Dihydroxyphenylalanine Polymer**
}

\author{
By Paul Podsiadlo, Zhongqiang Liu, David Paterson, Phillip B. Messersmith, and Nicholas A. Kotov*
}

Nature has evolved materials that possess mechanical properties surpassing many man-made composites. Bones, teeth, spider silk, or nacre, are just a few well-known examples of biomaterials that exhibit exceptionally high tensile strengths, hardness, or toughness. ${ }^{[1-6]}$ These remarkable properties have driven scientists to study and model their architectures and compositions, from micro- to nanoscales, in the hope of developing analogous synthetic materials. Of these, probably the most studied is nacre. ${ }^{[4,7-15]}$ It is composed of $95 \%$ brittle $\mathrm{CaCO}_{3}$ plates with just a few percent of organic "glue", yet it is twice as hard and more than ca. 1000 times as tough as its constituent phases. ${ }^{[16]}$ These exceptional mechanical properties together with the macroscopic beauty and elegance of its nanoscale hierarchy serve as a model for design of high-performance materials.

Preparation of artificial analogs of nacre has been approached by using several different methods and the resulting materials capture some of the characteristics of the natural composite. ${ }^{[17-23]}$ In our own work, we have used a layerby-layer (LBL) assembly technique to prepare a nanostructured analogue of nacre from inorganic nanometer-sized sheets of $\mathrm{Na}^{+}$-Montmorillonite clay (C) and a polyelectrolyte, poly(diallyldimethylammonium chloride) (PDDA). ${ }^{[2]}$ The structure, deformation mechanism, and mechanical properties of this material were found to be comparable with those of natural nacre and lamellar bones (tensile strength, $\sigma=(100 \pm 10) \mathrm{MPa}$, and Young's modulus, $Y=(11 \pm 2) \mathrm{GPa})$. Contrary to other preparation techniques the LBL method is relatively simple and highly versatile in merging different

[*] Prof. N. A. Kotov, P. Podsiadlo, D. Paterson Department of Chemical Engineering, University of Michigan Ann Arbor, MI 48109 (USA)

E-mail: kotov@umich.edu

Dr. Z. Liu, Prof. P. B. Messersmith

Department of Biomedical Engineering, Northwestern University Evanston, IL 60208 (USA)

[**] N.A.K. thanks AFOSR, NSF, DARPA, and NRL for the support of this research. P.P. thanks the Fannie and John Hertz Foundation for support of his work through a graduate fellowship. The authors acknowledge the staff of the Electron Microscopy Analysis Laboratory (University of Michigan) and their sponsor, the National Science Foundation (NSF) through grant \#DMR-0320740. P.B.M. acknowledges support for this work from NIH (DE 14193) and NASA (URETI NCC-1-02037). Supporting Information is available online from Wiley InterScience or from the author. functionalities into a single composite. ${ }^{[25-27]}$ At the same time, a vast array of available assembly components allows us to generate alternative designs as a means of understanding the different interactions necessary for preparation of nacrelike composites with application-tailored mechanical responses.

LBL technique has proven to be an ideal method for preparation of multifunctional, nanostructured materials. Since its inception in $1990 \mathrm{~s},{ }^{[28]}$ there has been a virtual explosion in the amount of scientific literature in this subject. Similarly, LBL assembly of clays was also pioneered and further studied in the 1990 s by Ferguson's group. ${ }^{[29,30]}$ Since then, the LBL technique has been found to be applicable for the preparation of superhydrophobic surfaces, ${ }^{[31]}$ sensors and semipermeable membranes, ${ }^{[32-35]}$ drug and biomolecules delivery, ${ }^{[36,37]}$ optically active and responsive films, ${ }^{[38-40]}$ fuel cells and photovoltaic materials, ${ }^{[41,42]}$ biomimetic and bioresponsive coatings, ${ }^{[43]}$ semiconductors, ${ }^{[44,45]}$ catalysts, ${ }^{[46]}$ and magnetic devices, ${ }^{[26,47]}$ to name a few. All of the potential applications mentioned above also require both control and improvement of mechanical properties. Using the mix-and-match approach to LBL films, that is, stratified multilayers, ${ }^{[25,26,44]}$ the mechanical properties can be incorporated in virtually any LBL functionality, if a convenient pair of LBL partners is available. Similarly to our work on nanostructured nacre, we have also previously shown that preparation of high-strength LBL composites from single- and multiwalled carbon nanotubes (CNTs). ${ }^{[48,49]}$ They demonstrated mechanical properties as high as: $\sigma=220 \mathrm{MPa}$, and $Y=5 \mathrm{GPa}$, and are particularly suited for multifunctional stratified coatings with electrical conductivity.

Having at hand versatility of the LBL technique and potential for use in a wide array of applications, we have set out to improve the mechanical properties of our composite further. Clay nanosheets possess exceptionally high mechanical properties, with $Y$ calculated at ca. 250-260 GPa, ${ }^{[50]}$ which is two orders of magnitude greater than the mechanical properties of most clay nanocomposites achieved thus far. We have hypothesized that improving load transfer from the weak polymeric component to the inorganic nanosheets in our artificial nacre should increase the composite's mechanical properties. This required a polymer that would have a potentially stronger interaction with the clay than the ionic bonds in PDDA/C. For inspiration we have turned to another exceptional biomaterial, the unusual protein adhesive secreted by mussels. 
Mussels are notorious foulers of marine surfaces, for example, rocks, wood, metals, and even polymers, for which they secrete a byssal apparatus consisting of a series of protein threads that tether the organism onto a wet surface. Mussel holdfasts have been extensively studied by the Waite group, ${ }^{[51]}$ including the specialized mussel adhesive proteins (MAPs) found at the interface between the byssal thread and the surface. MAPs serve the role of cement, which upon secretion become rapidly solidified via chemical crosslinking into an insoluble plaque, tethering the animal to surfaces. A predominant feature of MAPS is the presence of L-3,4-dihydroxyphenylalanine (DOPA), ${ }^{[52]}$ a catecholic amino acid formed by posttranslational modification of tyrosine found in MAPs. ${ }^{[53]}$ DOPA has been implicated in crosslinking reactions leading to solidification of the liquid protein glue, ${ }^{[54-56]}$ for which there is a possible role for metal ions such as $\mathrm{Fe}^{3+}$ in the crosslinking reaction. ${ }^{[56,57]}$ Aside from glue crosslinking, DOPA is known to have high affinity for a variety of chemically distinct surfaces: organic and inorganic, via coordination, covalent, or hydrogen bonds. ${ }^{[58]}$

The simultaneous strong binding, versatility and hardening capability of DOPA prompted us to exploit it for preparing artificial nanostructured nacre in the hope of enhancing the interfacial clay-polymer interaction and to increase mechanical properties of the composite. Here we demonstrate, for the first time, preparation of a nanostructured composite having nacrelike architecture, which takes advantage of DOPA adhesion and crosslinking strength. We show that DOPA has a great effect on the strength of the nanocomposite, and the crosslinking ability allows for an even greater increase in the mechanical properties-three times in strength, ca. $40 \%$ in modulus, and four times in toughness.

Preparation of the DOPA-based nanocomposite was performed following similar parameters to those used for PDDAbased composite ${ }^{[24]}$ (see Experimental). As successful and dense adsorption of $\mathrm{C}$ on the DOPA-Lys-PEG (Lys = lysine; $\mathrm{PEG}=$ polyethylene glycol) surface is necessary for deposition of subsequent layers, atomic force microscopy (AFM) was used for characterizing the adsorbed $\mathrm{C}$ layer (Fig. 1). Similarly to our previous work, $\mathrm{C}$ platelets were observed to adsorb in the form of a densely packed layer with parallel orientation to the substrate (Fig. 1B and C). The high roughness seen in the picture is a result of short stacks of clay platelets, several sheets in thickness, which are either formed as a result of incomplete exfoliation of the clay, polymer-stimulated stacking, or stochastic build-up of adsorbing platelets. ${ }^{[59]}$ Subsequent multilayer buildup was characterized with UV-vis spectroscopy. Compilation of the spectra showed linear increase in absorbance indicating high uniformity of the multilayer (Fig. 2A). Plotting of the absorbance as a function of a bilayer number for the maximum of absorbance wavelength could be further fitted with a linear regression (Fig. 2C). The adsorp- tion continued in a uniform fashion for the entire assembly (see Supporting Information, Fig. S1).

For the purpose of mechanical properties evaluation, 200and 300-bilayer films were prepared on microscope glass slides. Subsequently, the films were treated with $0.5 \mathrm{M} \mathrm{Fe}\left(\mathrm{NO}_{3}\right)_{3}$ solution $(\mathrm{pH} \approx 3)$ in order to allow for crosslinking of DOPA. The choice of $\mathrm{Fe}^{3+}$ crosslinker was based on the work of Waite's and Wilker's groups, which showed that Fe may be an important crosslinking agent of DOPA in the natural environment. ${ }^{[56,57,60]} \mathrm{Fe}^{3+}$ forms complexes with DOPA, the stoichiometry of which depends on the $\mathrm{Fe}^{3+} / \mathrm{DOPA}$ ratio and the $\mathrm{pH}$ of the system. ${ }^{[56,61,62]}$ Furthermore, at alkaline $\mathrm{pH}$ values such as that of seawater (ca. 8), autoxidation of DOPA through radical species formation and, ultimately, covalent self-crosslinking of DOPAs is possible. Accordingly, after $30 \mathrm{~min}$ immersion of the glass slides in the $\mathrm{Fe}\left(\mathrm{NO}_{3}\right)_{3}$ solutions, the $\mathrm{pH}$ was raised from ca. 3 to 8 by drop-wise addition of $0.1 \mathrm{~m} \mathrm{NaOH}$ and the films were kept under these conditions for another $30 \mathrm{~min}$.

Once completed, glass slides were thoroughly washed with deionized (DI) water and dried. Visual inspection of the slides showed iron treated films acquired a reddish-brown hue, similar in color to the $\mathrm{Fe}\left(\mathrm{NO}_{3}\right)_{3}$ solution (Fig. 3A). The color change was the first indication of Fe:DOPA complex formation. This was further supported in UV-vis absorbance spectra of films at different stages of crosslinking (Fig. 3B). It has been shown that the different complexes of Fe:DOPA give rise to distinct absorbance bands. Wilker's group showed that a 1:1 complex has two relatively weak bands at $429 \mathrm{~nm}$ and $700 \mathrm{~nm}$. Similarly, the first band was also observed in the 

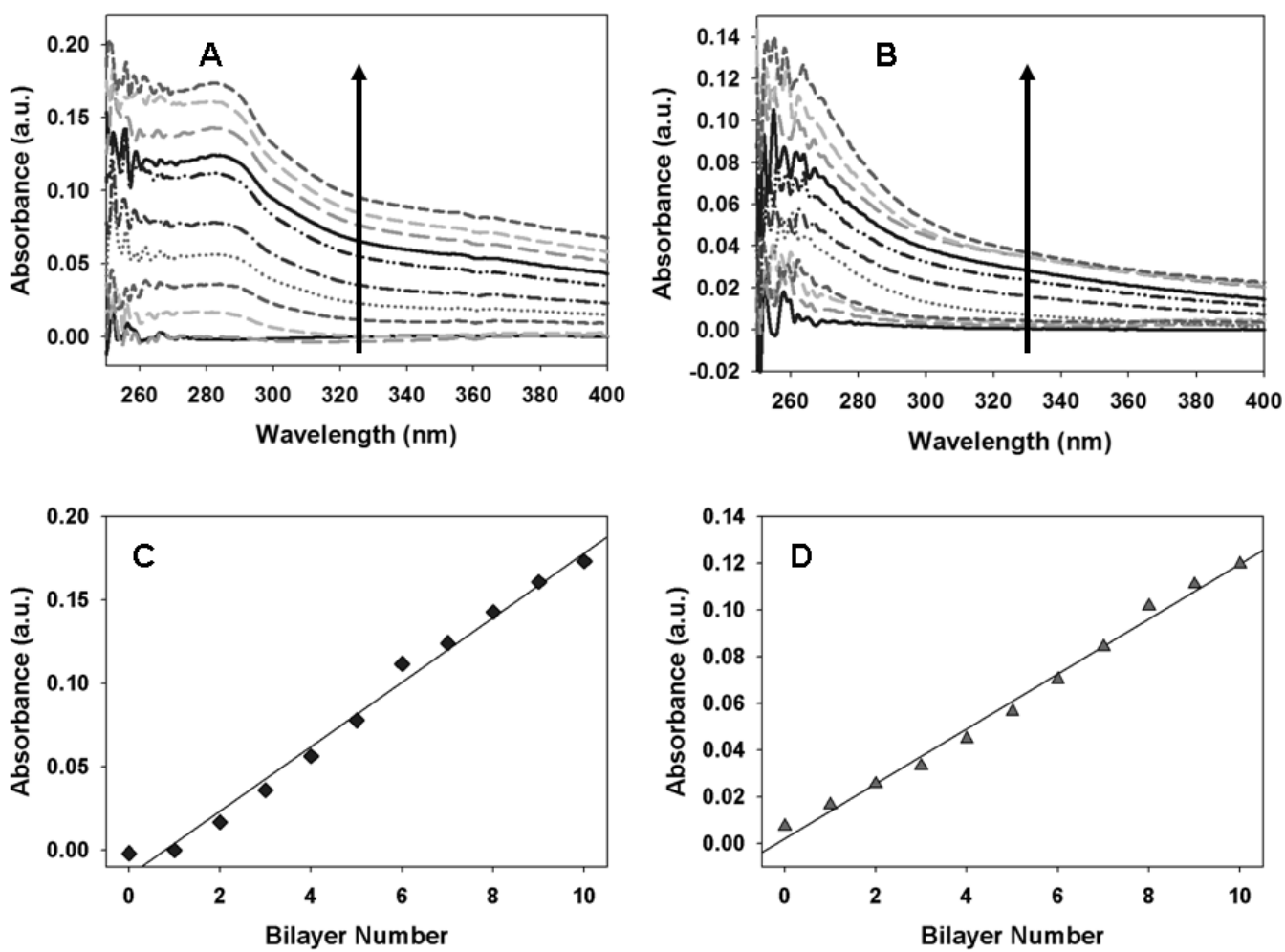

Figure 2. UV-vis spectra of DOPA-Lys-PEG/C and Lys-PEG/C films growth: A) compilation of full UV-vis absorbance spectra for deposition on a glass slide monitored after every bilayer (DOPA-Lys-PEG + C) for the first 10 bilayers (arrow indicates the direction of increase of absorbance after each bilayer), B) compilation of spectra for Lys-PEG/C for the first 10 bilayers, C) absorbance at $284 \mathrm{~nm}$ versus bilayer number for DOPA-Lys-PEG/C, and D) absorbance at $262 \mathrm{~nm}$ versus bilayer number for Lys-PEG/C.
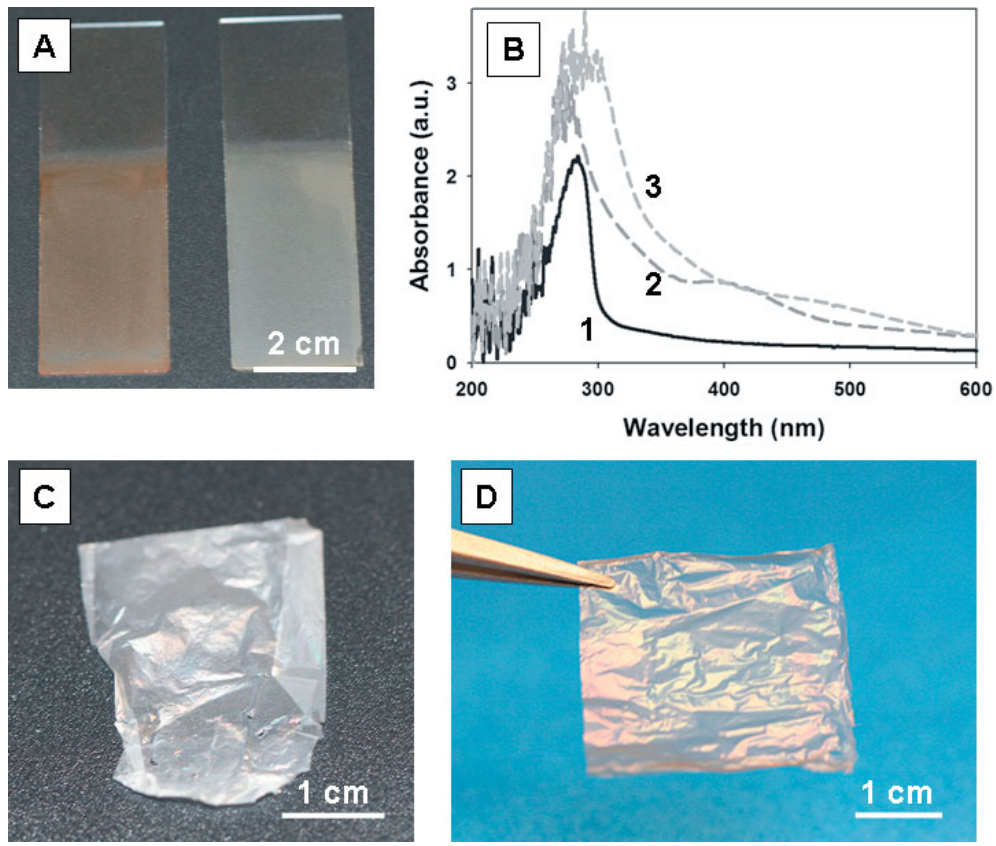

Figure 3. A) Digital photograph of 300 bilayer DOPA-Lys-PEG/C films on microscope glass slides with (left) and without (right) $\mathrm{Fe}^{3+}$ crosslinking, B) UV-vis spectra of 300 bilayer films of DOPA-Lys-PEG/C at different stages of DOPA:Fe complexation: 1) plain film, 2) $\mathrm{pH} \sim 3$, and 3) $\mathrm{pH} \sim 8, \mathrm{C}$ ) digital photograph of a 300 bilayer DOPALys-PEG/C free-standing film after separation from the glass slide, and D) digital photograph of a $\mathrm{Fe}^{3+}$ crosslinked 300 bilayer DOPA-Lys-PEG/C free-standing film.
$\mathrm{pH} \sim 3$ treated films in the form of a shoulder peak at ca. $400 \mathrm{~nm}$. The plain film showed only the DOPA peak. For the 1:2 and 1:3 complexes, the first band has been shown to be shifted down to $374 \mathrm{~nm}$ and subsequently back up to $483 \mathrm{~nm}$, respectively. Although the surrounding environment of the DOPA molecules in our system is very different from the previous studies and can affect the spectroscopic results, it is plausible that the shoulder peak we have observed is actually a result of a mixture of $1: 1$ and 1:2 complexes. For the films crosslinked further at $\mathrm{pH} \sim 8$, (the last curve in Fig. 3B), a broad and low intensity peak emerges between 400 and $600 \mathrm{~nm}$, which likely reflects either the 1:3 complex formation or oxidation of DOPA, as we have shown previously. ${ }^{[63]}$

Further proof of effective crosslinking came from evaluation of the mechanical properties of free-standing films (see Experimental). The 200 bilayer films appeared very thin and required careful handling. Although the plain films crumbled and tore into pieces, when we attempted to remove them from drying solvent, the crosslinked films showed strikingly good rigidity and stability. In comparison, the 300 bilayer films were much easier to handle, and the plain films, although still fragile, 
could be separated in entirety and reproducibly tested (Fig. 3C and D). A cross section of the films was characterized with scanning electron microscopy (SEM). The films revealed a thickness of $(1.0 \pm 0.1) \mu \mathrm{m}$ and $(1.5 \pm 0.1) \mu \mathrm{m}$ for the 200 and 300 bilayer thick samples, respectively (Fig. 4A). The cross section also revealed a distinct layered structure, which is characteristic of C-based LBL films, as $\mathrm{C}$ platelets form tightly packed layers parallel to the deposition surface.

Mechanical properties were evaluated by stretching strips of the films to failure and plotting the true stress-versus-strain curves. Typical stress-strain curves are presented in Figure 5A and the mechanical properties are summarized in Table 1. Similarly to our previous results with PDDA/C nanocomposite, the DOPA-Lys-PEG/C films also exhibit initial plastic deformation followed by an abrupt hardening region as can be seen in the initial strain region $(0-0.5 \%$ strain) in Figure $5 \mathrm{~A}$. The plastic deformation region in DOPA films is not as pronounced as for PDDA/C, however the strain in the hardened region is almost six times greater than in the DOPA-Lys$\mathrm{PEG} / \mathrm{C}$ films after crosslinking. One explanation for the lack of hardening region can be found in the fact that the DOPALys-PEG polymer contains a very high amount of PEG polymer that can be considered as weakly interacting in the LBL-C system. AFM imaging of $\mathrm{C}$ on pure, linear PEG showed sparse clay platelets (see Supporting Information, Fig. S2). In PDDA/C films, high density of charges and flexibility of PDDA molecules allowed for coiling of the polymer and formation of ionic bridges in the polymeric matrix. A large amount of charges gave a strong interaction with the $\mathrm{C}$ platelets and ionic bridging was found to be responsible for the observed toughening behavior.

The ultimate strength of the crosslinked composite was twice as high as that of the PDDA/C film. The tensile strength for a 200 bilayer film of PDDA/C (thickness of ca. $4.9 \mu \mathrm{m}$ )
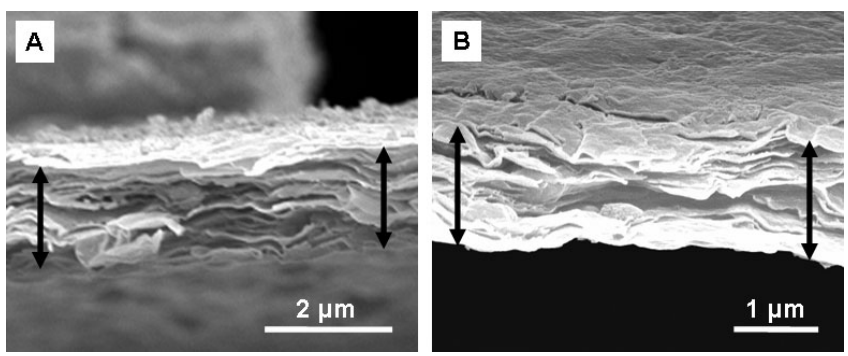

Figure 4. SEM cross-sectional view of 300 bilayer, $\mathrm{Fe}^{3+}$ crosslinked films of A) DOPA-Lys-PEG/C and B) Lys-PEG/C. Arrows indicate the cross section of the films. The slight separation of the layers seen in (B) is caused by a shearing force resulting from cutting samples with a razor blade during sample preparation.
Table 1. Summary of mechanical properties for 300 bilayers DOPA-LysPEG/C and Lys-PEG/C composites obtained from stress-strain responses. $\mathrm{Fe}^{3+}$ crosslinking corresponds to a $\mathrm{pH} \sim 8$ reaction.

\begin{tabular}{|c|c|c|c|c|}
\hline & $\begin{array}{c}\text { Tensile } \\
\text { strength, } \sigma \\
\text { [MPa] }\end{array}$ & $\begin{array}{c}\text { Young's } \\
\text { modulus, Y } \\
\text { [GPa] }\end{array}$ & $\begin{array}{c}\text { Ultimate } \\
\text { strain, } \varepsilon \\
{[\%]}\end{array}$ & $\begin{array}{c}\text { Toughness } \\
{\left[\mathrm{M} \mathrm{m}^{-3}\right]}\end{array}$ \\
\hline $\mathrm{PDDA} / \mathrm{C}$ & $100 \pm 10$ & $11 \pm 2$ & $8.4 \pm 0.7$ & $\sim 0.5$ \\
\hline DOPA-Lys-PEG/C & $77 \pm 29$ & $4.6 \pm 1.0$ & $2.6 \pm 0.9$ & $1.0 \pm 0.6$ \\
\hline DOPA-Lys-PEG/C + $\mathrm{Fe}^{3+}$ & $200 \pm 28$ & $6.8 \pm 0.9$ & $3.8 \pm 0.7$ & $4.2 \pm 1.2$ \\
\hline Lys-PEG/C & $39 \pm 27$ & $2.2 \pm 1.1$ & $2.3 \pm 1.7$ & $0.7 \pm 0.8$ \\
\hline Lys-PEG $/ C+\mathrm{Fe}^{3+}$ & $25 \pm 10$ & $2.2 \pm 0.6$ & $1.5 \pm 0.8$ & $0.2 \pm 0.2$ \\
\hline
\end{tabular}

was ca. $109 \mathrm{MPa}$, however for a film with comparable thickness, 50 bilayers (ca. $1.2 \mu \mathrm{m}$ ), the strength was only ca. $95 \mathrm{MPa}$. Even the films without iron crosslinking displayed strengths of ca. $80 \mathrm{MPa}$, which are approaching that of PDDA/C. The Young's modulus however was greatly reduced. For the PDDA/C nanocomposite $Y \approx 13 \mathrm{GPa}$ for a 200 bilayer film and it was ca. $9 \mathrm{GPa}$ for the $1.2 \mu \mathrm{m}$ film, whereas for the DOPA films it was only ca. 5 before and $7 \mathrm{GPa}$ after crosslinking. Once again, this result can be attributed to a high amount of noninteracting PEG polymer, which is caused by the composition and architecture of the DOPA-containing polymer analog of MAP. The LBL films with DOPA have a significantly higher toughness, which can especially be seen from the difference in the stressstrain curves. For the PDDA/C nanocomposites the toughness varies between ca. $0.5-0.6 \mathrm{MJ} \mathrm{m}^{-3}$, whereas for DOPA-Lys-PEG/C the toughness is about $2 \times$ greater, at $(1 \pm 0.6) \mathrm{MJ} \mathrm{m}^{-3}$ and $8 \times$ greater for the crosslinked composite at $(4.2 \pm 1.2) \mathrm{MJ} \mathrm{m}^{-3}$. We believe that this is a synergistic effect of the smaller amount of polymer-C interactions, which lead to reduced stiffness (slope of the curve) and greater strain, as well as being caused by DOPA crosslinking, which produces a $3 \mathrm{D}$ polymer network trapping the $\mathrm{C}$ platelets and reducing the chance of premature failure of the composite. 
Overall, effectiveness of a small amount of DOPA is surprising and significant and thus prompted us to study this interaction closer. For comparison, we synthesized an identical 4-armed PEG polymer, except without the DOPA groups-a "Lys-PEG" polymer, and prepared nanocomposite films following the same steps. Characterization of the new films showed that similarly to the DOPA-Lys-PEG polymer, the Lys-PEG/C assembly had uniform growth when observed with UV-vis spectroscopy (Fig. 2B and D). However, a clear difference could be seen in the position of the maximum absorbance peaks between the two different polymers (Fig. 2A and B). As expected, the Lys-PEG/C was deprived of absorbance at ca. $280 \mathrm{~nm}$, with its own maximum, caused by C alone, at ca. $260 \mathrm{~nm}$. Contrary to pure PEG, the Lys-PEG/C films were successfully grown and separated from the substrate into free-standing films. Characterization of the cross section of the films revealed a similar growth increment with a final thickness of ca. $1.6 \mu \mathrm{m}$ for a 300 bilayer film, which is very close to the DOPA-Lys-PEG/C composite (Fig. 4B). The mechanical properties revealed a striking difference and gave one of the most important results of this comparison. The Lys-PEG/C films showed nearly half the ultimate strength as compared to the DOPA-containing composite, with ultimate strength approaching ca. $40 \mathrm{MPa}$. The ultimate strain showed a comparable value to the DOPA-containing polymer (before $\mathrm{Fe}^{3+}$ crosslinking), ca. $2.3 \%$, however $Y$ was less than half: 2.2 GPa versus 4.6 GPa. The difference in strength and modulus can be attributed to increased interfacial interaction and much more effective load transfer from the polymeric matrix to the stiff $\mathrm{C}$ platelets when DOPA is present. Literature reports show that the modulus of individual platelets can be as high as ca. $250-260 \mathrm{GPa},{ }^{[50]}$ hence it is reasonable to assume that increasing the strength of interaction with $\mathrm{C}$ platelets should increase the modulus and strength of the composite effectively. This should be especially true in our composite where loading of the C platelets is very high, ca. $65 \mathrm{wt} \%$ (see Supporting Information, Fig. S3).

Another important result of this comparison is the effect of $\mathrm{Fe}^{3+}$ crosslinking the polymeric matrix in the nanocomposite and ultimately its effect on the mechanical properties. Figure $5 \mathrm{~A}$ is a comparison of typical curves for all of the films with and without crosslinking and Table 1 summarizes the resulting mechanical properties. Unlike in the DOPA-containing films, addition of $\mathrm{Fe}^{3+}$ actually decreased the mechanical properties of the Lys-PEG/C film: the strength decreased from ca. 40 to $25 \mathrm{MPa}$ and the ultimate strain decreased by nearly $1 \%$. A potential explanation for this is that the trivalent $\mathrm{Fe}^{3+}$ ions displace some of the monovalent Lys groups from the surface and decrease the bonding of the polymer with C platelets. If the same effect is present in the DOPAcontaining composite, this would mean that the strength of the DOPA-C platelets interaction is even stronger then could be deduced from the strength results, as some of the Lys residues could also be displaced.

At the molecular level DOPA serves a dual role: 1) an anchor that attaches the polymer to the platelets and 2) a bridge between polymer chains forming a crosslinked 3D matrix via $\mathrm{Fe}^{3+}$ treatment followed by exposure to alkaline $\mathrm{pH}$. As can be deduced from the crosslinking effect on mechanical properties, some of the DOPA molecules are attached to the surface and others are involved in bonding with other chains. A potential mechanism of deformation is that upon application of load to the films, the weaker bonds, PEG-C and Lys-C, are broken first, while the DOPA maintains its stronger bond to the $\mathrm{C}$ platelets. Only when much greater force is applied to these bonds does the composite fail and rupture.

Finally, as DOPA-containing marine adhesives show excellent stability under aqueous conditions we have tested our crosslinked films under varied humidity. Figure 5B summarizes results of the test. The composite gradually transitions from brittle to highly ductile as the humidity increases. This is different from the behavior of the true MAP, which is again quite likely because of the PEG segments, but, at the same time, is very similar to the behavior of PDDA/C films. More interestingly, the behavior is reversible with very fast transition time. In a simple experiment, a water-soaked film was simply dried off with a paper towel and immediately tested under ambient conditions. When tested, the film showed exactly the same behavior as without wetting.

In summary, we described the preparation of a novel nanostructured composite film that takes advantage of two different natural materials: layered nacre and the marine adhesive of mussels. Overall, this work is a first example of the fusion of two seemingly distinct concepts found in Nature into a unique composite with excellent mechanical properties. Just as in mussels, we found that DOPA molecules impart unusual adhesive strength to the clay composite and the hardening mechanism found in the natural "cement" plays an equally important role in strengthening of our "nanostructured nacre'. In comparison to our previous work with PDDA, we found that even a small amount of DOPA has a dramatic effect on the mechanical properties: the ultimate strength increased $2 \times$ and the toughness by ca. $8 \times$.

\section{Experimental}

Materials: $\mathrm{Na}^{+}$-Montmorillonite, "Cloisite $\mathrm{Na}^{+}$" $(\mathrm{C})$, was purchased from Southern Clay Products (Gonzales, TX). Microscope glass slides used for the deposition were obtained from Fisher Scientific. Hydrogen peroxide and concentrated sulfuric acid used in the piranha cleaning solution were both purchased from Sigma-Aldrich. Concentrated hydrofluoric acid (HF) was obtained from Sigma-Aldrich and a $1 \mathrm{vol} \% \mathrm{HF}$ solution, used for the preparation of free-standing films, was prepared by appropriately diluting the stack solution with DI water. Isopropyl alcohol, American Chemical Society (ACS) grade, used in the separation of free-standing films was purchased from Sigma-Aldrich. $\mathrm{Fe}\left(\mathrm{NO}_{3}\right)_{3}$ solid and $\mathrm{NaOH}$ pellets were obtained from Sigma-Aldrich. 4-arm PEG-amine was purchased from SunBio, Inc. (Orinda, CA). DOPA(Ac2)-NCA and Lys(Fmoc)-NCA were prepared by following reported procedures $[64,65]$. PEG with comparable weight-average molecular weight $M_{\mathrm{w}} \approx 15000 \mathrm{~g} \mathrm{~mol}^{-1}$ to the DOPA-containing polymer was purchased from Sigma-Aldrich.

Synthesis of 4-Armed DOPA-Lys-PEG Polymer: DOPA-Lys-PEG polymer was synthesized through ring-opening polymerization of $N$-carboxyanhydride (NCA) monomers of DOPA and Lys from the 
end groups of an amine-terminated 4-arm PEG polymer. $0.52 \mathrm{~g}$ of 4-arm PEG- $\mathrm{NH}_{2}$ was azeotropically dried with benzene and then transferred to a $100 \mathrm{~mL}$ air-free flask with DOPA(Ac2)-NCA $(0.37 \mathrm{~g})$ and Lys(Fmoc)-NCA $(0.48 \mathrm{~g})$. The flask was put under vacuum and then refilled with argon. After three cycles, $30 \mathrm{~mL}$ anhydrous THF was added through a cannula. The mixture was stirred at room temperature with argon protection for 5 days. The clear solution was dropped into cold ether and the light-gray precipitate was collected. To a $100 \mathrm{~mL}$ air-free flask were added the obtained precipitate and $30 \mathrm{~mL}$ dimethylformamide (DMF). After the solution was bubbled with argon for $40 \mathrm{~min}, 8 \mathrm{~mL}$ degassed piperidine was added through a cannula. The mixture was stirred at room temperature with argon protection for $1 \mathrm{~h}$. The solvent was reduced to ca. $10 \mathrm{~mL}$ by high vacuum, and then cold-dry ether was added. A light-brown precipitate was collected and dissolved in $0.1 \mathrm{~N} \mathrm{HCl}$. After dialysis (3500 Da cutoff point; $\left.1 \mathrm{Da} \approx 1.66 \times 10^{-27} \mathrm{~kg}\right)$ in acidic water $(\mathrm{HCl}, \mathrm{pH} 4.5)$, the solution was lyophilized to give a light-brown solid, yield $70 \%$. ${ }^{1} \mathrm{H}$ NMR $\left(500 \mathrm{MHz}, \mathrm{DMSO}-d_{6}\right): \delta 6.66-6.43\left(\mathrm{~m},-\mathrm{C}_{6} \mathrm{H}_{3}(\mathrm{OH})_{2}\right) ; 4.41-4.33(\mathrm{~m}$, $\left.\mathrm{NH}-\mathrm{CH}(\mathrm{CO})-\mathrm{CH}_{2} \mathrm{C}_{6} \mathrm{H}_{3}(\mathrm{OH})_{2}\right) ; 4.19\left(\mathrm{NH}-\mathrm{CH}(\mathrm{CO})-\left(\mathrm{CH}_{2}\right)_{4}-\mathrm{NH}_{2}\right)$; $2.98\left(\mathrm{br},-\mathrm{CH}-\mathrm{CHH}-\mathrm{C}_{6} \mathrm{H}_{3}(\mathrm{OH})_{2}\right), 2.81\left(\mathrm{~s},-\mathrm{CH}-\mathrm{CHH}-\mathrm{C}_{6} \mathrm{H}_{3}(\mathrm{OH})_{2}\right)$; 2.74 (br, $\left.\mathrm{NH}-\mathrm{CH}(\mathrm{CO})-\left(\mathrm{CH}_{2}\right)_{3}-\mathrm{CH}_{2}-\mathrm{NH}_{2}\right), 1.79(\mathrm{NH}-\mathrm{CH}(\mathrm{CO})-$ $\left.\mathrm{CH}_{2}\left(\mathrm{CH}_{2}\right)_{3}-\mathrm{NH}_{2}\right) ; 1.53\left(\mathrm{NH}-\mathrm{CH}(\mathrm{CO})-\left(\mathrm{CH}_{2}\right)_{2}-\mathrm{CH}_{2}-\mathrm{CH}_{2}-\mathrm{NH}_{2}\right)$; and $1.34\left(\mathrm{NH}-\mathrm{CH}(\mathrm{CO})-\mathrm{CH}_{2}-\mathrm{CH}_{2}-\left(\mathrm{CH}_{2}\right)_{2}-\mathrm{NH}_{2}\right)$. Molecular weight was determined by using gel-permeation chromatography (GPC), $\bar{M}_{\mathrm{w}}=16400 \mathrm{~g} \mathrm{~mol}^{-1}$. The DOPA content of the block copolymers was determined from the UV absorbance of polymer solutions in $12.1 \mathrm{~mm} \mathrm{HCl}$ at the maximum absorbance wavelength of the catechol (maximum wavelength, $\lambda_{\max }=280 \mathrm{~nm}$ ). Solutions containing known concentrations of free DOPA amino acid were used to construct the calibration curve. Using this method, DOPA content was determined to be $21.8 \mathrm{wt} \%\left(1.22 \mathrm{mmol} \mathrm{g}^{-1}\right)$, which is approximately $5.2 \mathrm{DOPA}$ amino acids per PEG arm. The Lys content was estimated from ${ }^{1} \mathrm{H}$ NMR through calculating the ratio of integral values of the peaks at 4.19 and 4.41-4.33, and found to be equimolar with respect to the DOPA content.

Synthesis of 4-Armed Lys-PEG Polymer: In a similar fashion, a DOPA-free Lys-PEG polymer was synthesized through ring-opening polymerization of $N$-carboxyanhydride (NCA) monomers of Lys(Fmoc)-NCA from the end groups of an amine-terminated 4-arm PEG polymer. $0.52 \mathrm{~g}$ of 4-arm PEG-NH2 was reacted with Lys(Fmoc)-NCA $(0.48 \mathrm{~g})$. A light-brown powder was obtained, yield $60 \%$. Molecular weight was determined by MALDI-TOF MS (Matrix-assisted-laser-desorption/ionization-time-of-flight mass spectrometry) [66]; to be 10146 for 4-arm PEG-NH ${ }_{2}$, and 11339 for synthesized Lys-PEG polymer, yielding an estimated Lys content of ca. 2.3 Lys amino acids per PEG arm.

Solutions: $0.5 \mathrm{wt} \%$ dispersion of C, used in the experiments, was prepared by dissolving $5 \mathrm{~g}$ of clay in $1 \mathrm{~L}$ of $18 \mathrm{M} \Omega \mathrm{cm}^{-1}$, pH $5.6 \mathrm{DI}$ water, under vigorous stirring for 1 week prior to use. Once stirring was finished, the dispersion was allowed to sediment for 1 day and the supernatant was collected and used in subsequent experiments. Solution of $\mathrm{Fe}^{3+}$ was prepared in the same DI water. Solution of the different polymers were prepared in $\mathrm{pH} 3$ DI water with $\mathrm{pH}$ adjusted using $1 \mathrm{~m} \mathrm{HCl}$ solution.

Preparation of DOPA-Lys-PEG/C, Lys-PEG/C, and PEG/C Thin Films: Preparation of the films consisted of following steps: i) immersion of the substrate into a $0.2 \%(\mathrm{w} / \mathrm{v})$ solution of the polymer (Fig. 1A) for $5 \mathrm{~min}(\mathrm{pH} 3)$, ii) rinsing with DI water $2 \times 1 \mathrm{~min}$ (pH 5.6), iii) drying with a stream of compressed air for $1 \mathrm{~min}$, iv) immersion into $0.5 \%(\mathrm{w} / \mathrm{v})$ aqueous dispersion of $\mathrm{C}$ for $5 \mathrm{~min}(\mathrm{pH} 10)$, v) rinsing with DI water $2 \times 1 \mathrm{~min}$, and finally vi) once again drying with a stream of compressed air for $1 \mathrm{~min}$. Prior to beginning deposition, the glass slides were cleaned by immersion in a "piranha" solution $\left(3: 1 \mathrm{H}_{2} \mathrm{SO}_{4} / \mathrm{H}_{2} \mathrm{O}_{2}\right.$, dangerous if contacted with organics) for $1 \mathrm{~h}$, followed by thorough rinsing with DI water. Preparation of the samples was accomplished using a StratoSequence IV, a robotic dipping machine, from nanoStrata Inc. (Tallahassee, FL). Free-standing films of the composites were isolated with $1 \mathrm{vol} \% \mathrm{HF}$ solution by utilizing a technique described in the previous publication [24]. Prior to testing, films were dried at $80^{\circ} \mathrm{C}$ and subsequently equilibrated at ambient conditions for several days prior to testing.

Instrumental Analysis: Polymer molecular weights were determined by using GPC or by using MALDI-TOF MS (Voyager system 6050, Applied Biosystems). GPC was performed on a DAWN EOS (Wyatt Technology) using Shodex-OH Pak columns in an aqueous mobile phase $(50 \mathrm{~mm}$ phosphate buffered saline (PBS), $0.1 \mathrm{M} \mathrm{NaCl}, 0.05 \%$ $\mathrm{NaN}_{3} ; \mathrm{pH}$ 6.0) and an Optilab DSP (Wyatt Technology) refractive-index detector. For molecular weight calculations, the experimentally determined $\mathrm{d} n / \mathrm{d} c$ (change in refractive index with concentration) value of mPEG-NH ${ }_{2}\left(M_{\mathrm{W}} 5000, \mathrm{~d} n / \mathrm{d} c=0.136\right)$ was used. The LBL process was monitored using an $8453 \mathrm{UV}$-vis Chem Station spectrophotometer from Agilent Technologies, with data collected after each additional (polymer/clay) bilayer deposition. The reference spectrum for the instrument was that of a fresh, piranha-cleaned glass slide and collected spectra of the adsorbed material were compiled into a single plot for comparison. AFM images were obtained using a NanoScope IIIa atomic force microscope from Veeco Instruments (Santa Barbara, CA). The instrument was operated in tapping mode and images were obtained using silicon nitride cantilever tips (NSC16/Cr-Au, MikroMasch). Imaging was performed on films deposited on top of Si wafers. The weight percentage of clay inside the free-standing films was determined with thermo-gravimetric analyzer Pyris 1 from PerkinElmer, with a temperature ramp-up rate of $10{ }^{\circ} \mathrm{Cmin}^{-1}$ while being purged with air. The sample size was ca. $0.1 \mathrm{mg}$. The mechanical properties of free-standing films were analyzed by obtaining load-displacement curves with mechanical strength tester $100 \mathrm{Q}$ from TestResources Inc. (Shakopee, MN) for at least ten samples. Tests were performed at a rate of $0.01 \mathrm{~mm} \mathrm{~s}^{-1}$ using a $1.1 \mathrm{lbf}$ force (ca. $5 \mathrm{~N}$ ) load cell. Test samples were ca. $1 \mathrm{~mm} \times 6-10 \mathrm{~mm}$ rectangular wide strips cut out from the freestanding films. The instrument was calibrated with a set of known weights. Humidity tests were performed by pitching a plastic tent over the instrument with humidity being adjusted with boiling water. The humidity was constantly controlled with a standard thermometer and humidity meter from Oregon Scientific. Samples were equilibrated under given conditions for $1 \mathrm{~h}$ prior to testing. $100 \%$ humidity was achieved by soaking samples prior to testing for $1 \mathrm{~h}$ and spraying water mist on the sample immediately before the test. SEM was used to characterize the cross-sectional dimensions of the free-standing films. The images were obtained with an FEI Nova Nanolab dual-beam focused ion beam (FIB) and scanning electron microscope. Because of the nonconductive nature of the specimens, a few nm thick layer of gold was sputtered onto the surface of the film prior to imaging.

Received: November 27, 2006 Revised: January 13, 2007 Published online: March 1, 2007

[1] K. J. Coyne, X. X. Qin, J. H. Waite, Science 1997, 277, 1830

[2] J. D. Currey, Symp. Soc. Exp. Biol. 1980, 34, 75.

[3] J. Currey, Nature 2001, 414, 699.

[4] R. Z. Wang, Z. Suo, A. G. Evans, N. Yao, I. A. Aksay, J. Mater. Res. 2001, 16, 2485.

[5] Z. Shao, F. Vollrath, Nature 2002, 418, 741

[6] R. V. Lewis, Chem. Rev. 2006, 106, 3762.

[7] I. A. Aksay, M. Trau, S. Manne, I. Honma, N. Yao, L. Zhou, P. Fenter, P. M. Eisenberger, S. M. Gruner, Science 1996, 273, 892.

[8] B. L. Smith, T. E. Schaffer, M. Viani, J. B. Thompson, N. A. Frederick, J. Kind, A. Belcher, G. D. Stucky, D. E. Mors, P. K. Hansma, Nature 1999, 399, 761.

[9] M. Rousseau, E. Lopez, P. Stempfle, M. Brendle, L. Franke, A. Guette, R. Naslain, X. Bourrat, Biomaterials 2005, 26, 6254.

[10] M. Rousseau, E. Lopez, A. Coute, G. Mascarel, D. C. Smith, R. Naslain, X. Bourrat, J. Struct. Biol. 2005, 149, 149.

[11] K. S. Katti, D. R. Katti, S. M. Pradhan, A. Bhosle, J. Mater. Res. 2005, 20, 1097.

[12] F. Song, A. K. Soh, Y. L. Bai, Biomatererials 2003, 24, 3623. 
[13] N. Nassif, N. Pinna, N. Gehrke, M. Antonietti, C. Jaeger, H. Coelfen, Proc. Natl. Acad. Sci. USA 2005, 102, 12653.

[14] A. G. Evans, Z. Suo, R. Z. Wang, I. A. Aksay, M. Y. He, J. W. Hutchinson, J. Mater. Res. 2001, 16, 2475.

[15] X. Li, W. C. Chang, Y. J. Chao, R. Wang, M. Chang, Nano Lett. 2004, 4,613

[16] A. P. Jackson, J. F. V. Vincent, R. M. Turner, Proc. R. Soc. London Ser. $B$ 1988, 234, 415.

[17] A. Sellinger, P. M. Weiss, N. Anh, Y. Lu, R. A. Assink, W. Gong, C. J. Brinker, Nature 1998, 394, 256.

[18] S. Deville, E. Saiz, R. K. Nalla, A. P. Tomsia, Science 2006, 311, 515

[19] X. Zhang, C. Liu, W. Wu, J. Wang, Mater. Lett. 2006, 60, 2086.

[20] D. Volkmer, M. Harms, L. Gower, A. Ziegler, Angew. Chem. Int. Ed. 2005, 44, 639, 639.

[21] G. Pezzotti, S. M. F. Asmus, L. P. Ferroni, S. Miki, J. Mater. Sci. Mater. Med. 2002, 13, 783.

[22] C. A. Wang, Y. Huang, Q. Zan, H. Guo, S. Cai, Mat. Sci. Eng. C. 2000, 11,9 .

[23] S. Zhang, J. Zhang, Z. Zhang, H. Dang, W. Liu, Q. Xue, Mater. Lett. 2004, 58, 2266.

[24] Z. Tang, N. A. Kotov, S. Magonov, B. Ozturk, Nat. Mater. 2003, 2, 413.

[25] P. Podsiadlo, S. Paternel, J. M. Rouillard, Z. Zhang, J. Lee, J. W. Lee, E. Gulari, N. A. Kotov, Langmuir 2005, 21, 11915.

[26] A. Mamedov, J. Ostrander, F. Aliev, N. A. Kotov, Langmuir 2000, $16,3941$.

[27] O. Kachurina, E. Knobbe, T. L. Metroke, J. W. Ostrander, N. A. Kotov, Int. J. Nanotechnol. 2004, 1, 347.

[28] G. Decher, Science 1997, 277, 1232.

[29] E. R. Kleinfeld, G. S. Ferguson, Science 1994, 265, 370.

[30] G. S. Ferguson, E. R. Kleinfield, Adv. Mater. 1995, 7, 414.

[31] L. Zhai, M. C. Berg, F. C. Cebeci, Y. Kim, J. M. Milwid, M. F. Rubner, R. E. Cohen, Nano Lett. 2006, 6, 1213.

[32] D. L. Ellis, M. R. Zakin, L. S. Bernstein, M. F. Rubner, Anal. Chem. 1996, 68,817

[33] T. R. Farhat, J. B. Schlenoff, Langmuir 2001, 17, 1184.

[34] C. A. Constantine, S. V. Mello, A. Dupont, X. Cao, D. Santos, Jr., O. N. Oliveira, Jr., F. T. Strixino, E. C. Pereira, T. C. Cheng, J. J. Defrank, R. M. Leblanc, J. Am. Chem. Soc. 2003, 125, 1805.

[35] E. R. Kleinfeld, G. S. Ferguson, Chem. Mater. 1995, 7, 2327.

[36] K. C. Wood, H. F. Chuang, R. D. Batten, D. M. Lynn, P. T. Hammond, Proc. Natl. Acad. Sci. USA 2006, 103, 10207.

[37] J. Zhang, L. S. Chua, D. M. Lynn, Langmuir 2004, 20, 8015.

[38] J. Hiller, J. D. Mendelsohn, M. F. Rubner, Nat. Mater. 2002, 1, 59
[39] D. M. DeLongchamp, P. T. Hammond, Adv. Funct. Mater. 2004, 14, 224.

[40] T. Cassagneau, T. E. Mallouk, J. H. Fendler, J. Am. Chem. Soc. 1998, 120,7848

[41] H. Tokuhisa, P. T. Hammond, Adv. Funct. Mater. 2003, 13, 831.

[42] T. R. Farhat, P. T. Hammond, Adv. Funct. Mater. 2005, 15, 945.

[43] J. Zhang, B. Senger, D. Vautier, C. Picart, P. Schaaf, J. C. Voegel, P. Lavalle, Biomaterials 2005, 26, 3353.

[44] A. A. Mamedov, A. Belov, M. Giersig, N. N. Mamedova, N. A. Kotov, J. Am. Chem. Soc. 2001, 123, 7738 .

[45] D. Wang, A. L. Rogach, F. Caruso, Nano Lett. 2002, $2,857$.

[46] Y. Shen, J. Y. Liu, J. G. Jiang, B. F. Liu, S. J. Dong, J. Phys. Chem. B 2003, 107, 9744.

[47] A. J. Nolte, M. F. Rubner, R. E. Cohen, Langmuir 2004, 20, 3304

[48] A. A. Mamedov, N. A. Kotov, M. Prato, D. M. Guldi, J. P. Wicksted, A. Hirsch, Nat. Mater. 2002, 1, 190.

[49] M. Olek, J. Ostrander, S. Jurga, H. Moehwald, N. Kotov, K. Kempa, M. Giersig, Nano Lett. 2004, 4, 1889.

[50] O. L. Manevitch, G. C. Rutledge, J. Phys. Chem. B 2004, 108, 1428.

[51] J. Waite, N. Andersen, S. Jewhurst, C. Sun, J. Adhes. 2005, 81, 297.

[52] J. H. Waite, M. L. Tanzer, Science 1981, 212, 1038.

[53] J. H. Waite, J. Biol. Chem. 1983, 258, 2911.

[54] M. Yu, J. Hwang, T. J. Deming, J. Am. Chem. Soc. 1999, 121, 5825.

[55] L. A. Burzio, J. H. Waite, Biochemistry 2000, 39, 11147.

[56] M. J. Sever, J. T. Weisser, J. Monahan, S. Srinivasan, J. J. Wilker, Angew. Chem. Int. Ed. 2004, 43, 448.

[57] S. W. Taylor, D. B. Chase, M. H. Emptage, M. J. Nelson, J. H. Waite, Inorg. Chem. 1996, 35, 7572 .

[58] H. Lee, N. F. Scherer, P. B. Messersmith, Proc. Natl. Acad. Sci. USA 2006, 103, 12999.

[59] N. A. Kotov, T. Haraszti, L. Turi, G. Zavala, R. E. Geer, I. Dekany, J. H. Fendler, J. Am. Chem. Soc. 1997, 119, 6821.

[60] J. Monahan, J. J. Wilker, Langmuir 2004, 20, 3724.

[61] S. W. Taylor, G. W. Luther, III, J. H. Waite, Inorg. Chem. 1994, 33, 5819.

[62] M. J. Sever, J. J. Wilker, Dalton Trans. 2006, 813

[63] B. P. Lee, J. L. Dalsin, P. B. Messersmith, Biomacromolecules 2002, 3, 1038 .

[64] W. D. Fuller, M. S. Verlander, M. Goodman, Biopolymers 1976, 15, 1869.

[65] W. D. Fuller, M. S. Verlander, M. Goodman, Biopolymers 1978, 17, 2939.

[66] G. Montaudo, M. S. Montaudo, C. Puglisi, F. Samperi, Macromolecules 1995, 28, 4562. 